Article

\title{
Revealing the Fingerprint of Climate Change in Interannual NDVI Variability among Biomes in Inner Mongolia, China
}

\author{
Linghui Guo ${ }^{1}$, Liyuan Zuo ${ }^{2}$, Jiangbo Gao ${ }^{2,3, * \mathbb{C}}$, Yuan Jiang ${ }^{2}$, Yongling Zhang ${ }^{4}$, Shouchen Ma ${ }^{1}$, \\ Youfeng Zou ${ }^{1}$ and Shaohong $\mathrm{Wu}^{2}$ (D) \\ 1 School of Surveying and Land Information Engineering, Henan Polytechnic University, \\ Jiaozuo 454000, China; guolinghui@hpu.edu.cn (L.G.); mashouchen@hpu.edu.cn (S.M.); \\ zouyf@hpu.edu.cn (Y.Z.) \\ 2 Key Laboratory of Land Surface Pattern and Simulation, Institute of Geographic Sciences and Natural \\ Resources Research, Chinese Academy of Sciences, Beijing 100101, China; zuoly.17s@igsnrr.ac.cn (L.Z.); \\ jiangy.18s@igsnrr.ac.cn (Y.J.); wush@igsnrr.ac.cn (S.W.) \\ 3 Academy of Plateau Science and Sustainability, Xining 810016, China \\ 4 Emergency Management School, Henan Polytechnic University, Jiaozuo 454000, China; \\ zhyongling@hpu.edu.cn \\ * Correspondence: gaojiangbo@igsnrr.ac.cn
}

Received: 29 February 2020; Accepted: 19 April 2020; Published: 23 April 2020

check for updates

\begin{abstract}
An understanding of the response of interannual vegetation variations to climate change is critical for the future projection of ecosystem processes and developing effective coping strategies. In this study, the spatial pattern of interannual variability in the growing season normalized difference vegetation index (NDVI) for different biomes and its relationships with climate variables were investigated in Inner Mongolia during 1982-2015 by jointly using linear regression, geographical detector, and geographically weighted regression methodologies. The result showed that the greatest variability of the growing season NDVI occurred in typical steppe and desert steppe, with forest and desert most stable. The interannual variability of NDVI differed monthly among biomes, showing a time gradient of the largest variation from northeast to southwest. NDVI interannual variability was significantly related to that of the corresponding temperature and precipitation for each biome, characterized by an obvious spatial heterogeneity and time lag effect marked in the later period of the growing season. Additionally, the large slope of NDVI variation to temperature for desert implied that desert tended to amplify temperature variations, whereas other biomes displayed a capacity to buffer climate fluctuations. These findings highlight the relationships between vegetation variability and climate variability, which could be used to support the adaptive management of vegetation resources in the context of climate change.
\end{abstract}

Keywords: Inner Mongolia; normalized difference vegetation index (NDVI); interannual variability; coefficient of variation

\section{Introduction}

As the most important component of the terrestrial ecosystem, vegetation plays an important role in global hydrologic, energy, and biogeochemical cycles [1-3]. In recent years, rapid global warming as well as an increased frequency, intensity, and duration of climate extremes have profoundly affected and will continue to strongly impact vegetation dynamics and functions [4,5]. Therefore, a comprehensive assessment of climate-related variations in vegetation activity at biome and regional scales is of 
significance for providing a critical scientific basis of coping with and adaptating to climate change, and has been attracting much attention from the scientific community and the government $[6,7]$.

A great number of studies have explored vegetation dynamics and its responses to climate change at different spatial scales [4,8-10]. However, most of them focused mainly on the long-term trend and potential driving factors [11]. In comparison, our understanding of responses of interannual vegetation variability to climate fluctuations is limited [12]. Interannual variability, as a crucial indicator of vegetation stability to external disturbances, is of major importance to assess the effects of climate variability on vegetation $[13,14]$. Recent studies reported that climate variability is a key constraint on vegetation productivity across global pastures and could be responsible for $32 \%-39 \%$ of the global crop yield variability $[14,15]$. However, the responses of vegetation variability to climatic determinants may be dependent on the spatial heterogeneity of climatic conditions and biomes. For example, Kawabata et al. found that interannual vegetation activity was positively correlated with precipitation in arid and semi-arid areas, whereas it was negatively correlated or not correlated with precipitation in middle-high latitudes and tropical zones [16]. In addition, vegetation types may buffer the impacts of climate fluctuations in some regions [6] and amplify the variability in others [17]. It may be difficult to extrapolate existing findings to other regions, and a comprehensive and accurate understanding of the vegetation response to climate variation in different regions is thus critical for deepening our knowledge of the interaction between vegetation and climate change. Moreover, some studies have found that the largest variation occurred in the desert biome, while others argued it was most variable in grassland [6,12]. The patterns of interannual vegetation variability across biomes need to be explored further. The normalized difference vegetation index (NDVI) is strongly related to chlorophyll content and leaf area, and has been suggested as a useful predictor of vegetation activity [18,19]. Especially, the NDVI dataset from the Global Inventory Modeling and Mapping Studies (GIMMS), which has been proven to be the longest remotely sensed time series data, could provide unique opportunities for the exploration of long-term vegetation variability $[11,20]$.

Inner Mongolia is marked by a gradual change of vegetation from desert in the west to forests in the east due to the steep east-west gradient in hydrothermal conditions. It is an ideal platform for studying the response of vegetation to climate change. Therefore, using 34 years of NDVI time series derived from GIMMS, the main purpose of this study was to address: (1) The spatial patterns of interannual variability of NDVI for different biomes across Inner Mongolia at the growing season and monthly scales; (2) the potential responses of interannual variability of NDVI on climate fluctuation; and (3) the time lag effects of these climate variables.

\section{Data and Methods}

\subsection{Study Area}

Inner Mongolia, located in the northern part of China, is a vast area of $1.183 \times 10^{6} \mathrm{~km}^{2}$, comprising $12.3 \%$ of Chinese territory (Figure 1). The region is dominated by monsoon climate patterns that are controlled by continental Eurasian high- and low-pressure cells. During the summer, warm and humid air from the Pacific contributes to high temperatures and variable rainfall. In the winter, the region is affected by strong dry and cold northwesterly winds regulated by the Siberian-Mongolian atmospheric high-pressure cell [21]. Annual precipitation varies from approximately $50 \mathrm{~mm}$ in the southwest to $500 \mathrm{~mm}$ in the northeast, with an overall average precipitation of approximately $150 \mathrm{~mm}$. Similarly, the annual mean temperature varies along a strong southwest-northeast temperature gradient from approximately $10{ }^{\circ} \mathrm{C}$ in the southwest to less than $-3{ }^{\circ} \mathrm{C}$ in the northeast. According to Wu et al., Inner Mongolia can be divided from southwest to northeast into four major zones [22]. A temperate arid region in the southwest is dominated by a desert biome. A temperate semi-arid region occupying most of the central area, from approximately $40^{\circ} \mathrm{N}$ to $50^{\circ} \mathrm{N}$ latitude and $110^{\circ} \mathrm{E}$ to $120^{\circ} \mathrm{E}$ longitude, is dominated by steppe and fragmented areas of crop land. Finally, temperate humid and temperate sub-humid regions, occurring mainly in the northeast, are dominated by a forest biome. 


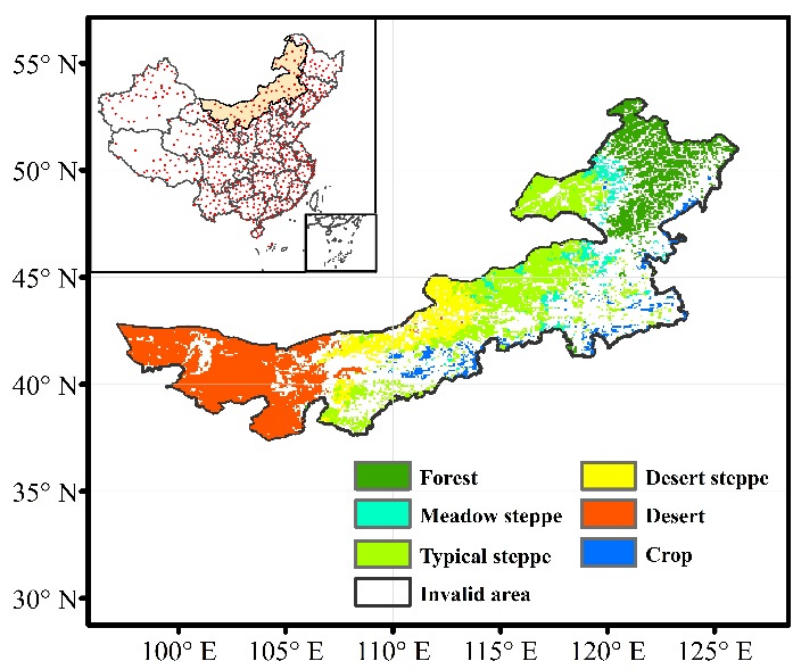

Figure 1. Vegetation types in Inner Mongolia. The insert indicates the location of the study area in China and the locations of 604 meteorological stations used in the study.

\subsection{Dataset}

The NDVI dataset was the latest updated version of the third generation Global Inventory Monitoring and Modeling System (GIMMS NDVI 3g.v1, available at https://ecocast.arc.nasa.gov/data/ pub/gimms/3g.v1/ as nc4 files), with 15-day intervals and a spatial resolution of $8 \times 8 \mathrm{~km}$ during 1982-2015. To further decrease the effects of atmospheric and aerosol scattering, we developed a monthly NDVI dataset using the maximum value composite (MVC) method for each month, as in previous studies [23]. We produced the growing season NDVI dataset by averaging the monthly NDVI during April-October for each year, as several studies suggest vegetation growth begins in April and senescence in October across Inner Mongolia [24,25].

Monthly average temperature and average precipitation data during the period 1982-2015 were calculated using a thin plate smoothing spline function in ANUSPLIN 4.3, based on 604 climatic stations over China (Figure 1). This data had the same spatial resolution as that of the NDVI data.

Using the Atlas of China (scale, 1:1,000,000; http://www.resdc.cn), vegetation type was divided into four main biomes (forest, grassland, crop, and desert). Because of large regional east-west trending heterogeneities in the grasslands of the region, we divided the grassland biome into meadow steppe, typical steppe, and desert steppe types, according to the criteria of the Rangeland resource of China [26] (intra zonal vegetation types, such as meadows, were not considered in the study). The Atlas of China data were then converted to the same spatial resolution as that of the NDVI data set. To avoid biases related to the effects of land use change on NDVI values during the study period, we discarded pixels from the data set if land use change in the pixel area was evident during the period between the 1980s and 2000s. The criteria for rejecting pixels were based on land use patterns inferred from maps of Inner Mongolia available for the start and end of the study period (1980s and 2000s), provided by the Data Center for Resources and Environmental Sciences of the Chinese Academy of Sciences (DCRESCAS; http://www.resdc.cn) at a spatial resolution of $1 \mathrm{~km}$. In addition, to reduce the influence of land use heterogeneity on NDVI as much as possible, we rejected pixels if the area of the dominant land use type was less than $50 \%$ of the area of the pixel. Specifically, we began by extracting land use types for datasets from the 1980s and 2000s, then converted these data with the same resolution as that of the NDVI and masked each land use type of the two periods, to get the pixels without land use change during the 1980s and 2000s. We then used these pixels to mask the vegetation types obtained above. Results of the vegetation survey are presented in Figure 1. 


\subsection{Methods}

The coefficient of variation $(\mathrm{CV})$ is a statistical index describing the degree of a variable relative to its mean, and has been regarded as a useful indicator of interannual variability or an ecosystem $[6,13]$. In this study, the CV value was used to investigate the magnitudes of interannual variability of the NDVI, temperature, and precipitation during the period of 1982-2015. Pearson correlation analyses between the CV values of the NDVI and those of the two climate variables for each biome at growing season and monthly scales were applied to explore the impacts of climate variables on the interannual variation pattern of NDVI variability. The slope of the linear regression between CV values of the NDVI and those of the climate variable was determined as the response magnitude of the CV values of the NDVI to the variation in climate variables. In order to completely and deeply understand these spatial relationships, the geographical detector was then applied to identify the climatic determinants for each biome. In this approach, the q statistic was used to measure the correlation between CVs of the growing season NDVI and CVs of each climate variable, according to the consistency between their spatial distributions, without an assumption of linearity [27]. Moreover, we conducted geographically weighted regression (GWR) to explore the spatial relations of CV values of the growing season NDVI to the variability of different climatic factors within each biome. This method is helpful to reveal the spatial relations by addressing the issue of a spatial non-stationary process [19]. Additionally, we also calculated the Pearson correlations between the CVs of the monthly NDVI and those of climate variables in the previous month during the growing season for each biome in order to examine the time lag effects.

\section{Results}

\subsection{Spatial Patterns of NDVI Variability for Biomes}

\subsubsection{Patterns in the Growing Season}

Figure 2 illustrates the spatial patterns of CVs of the growing season NDVI, precipitation, and temperature in the study area during the period 1982-2015. Generally, the CV of the growing season NDVI showed dramatic variations (0.01-0.33), with a mean value of 0.07 . The entire middle area showed relatively large variations in the growing season $C V$ values, whereas the smaller CV values were mainly located in the northeast and southwest (Figure 2a). The CV of the growing season temperature showed a decreasing pattern from northeast to southwest, with a mean value of 0.05 (Figure 2b). In comparison, most of the central area exhibited relatively small variations in precipitation $(0.20-0.30)$, whereas the CV of the growing season precipitation became larger in the northwest part of the west and east region (Figure 2c).

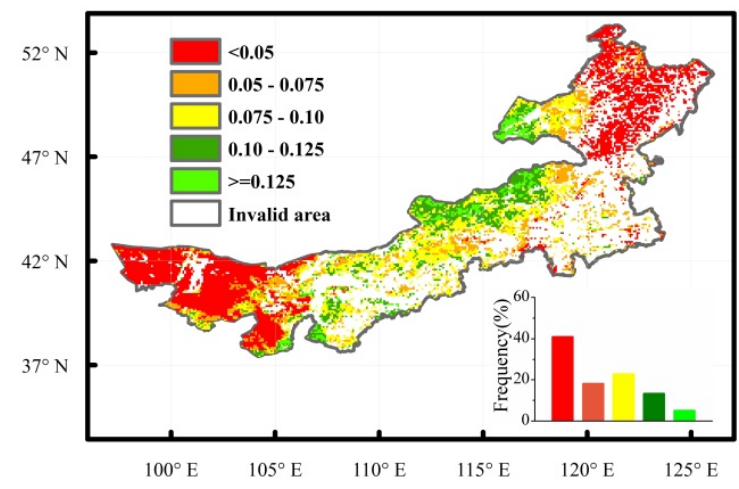

(a)

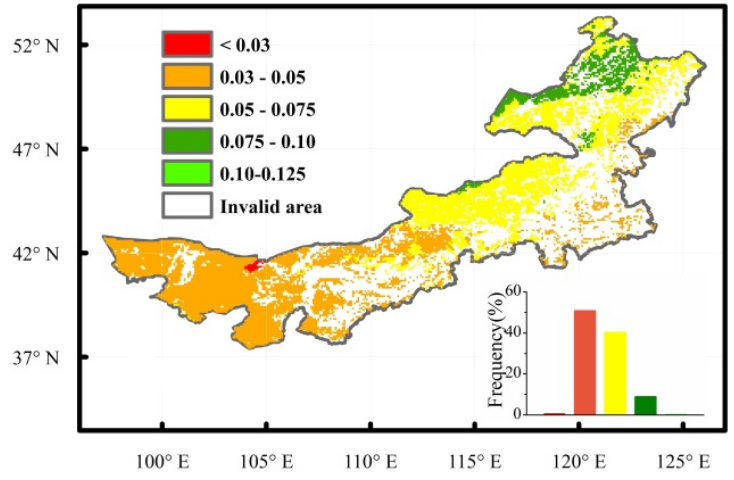

(b)

Figure 2. Cont. 


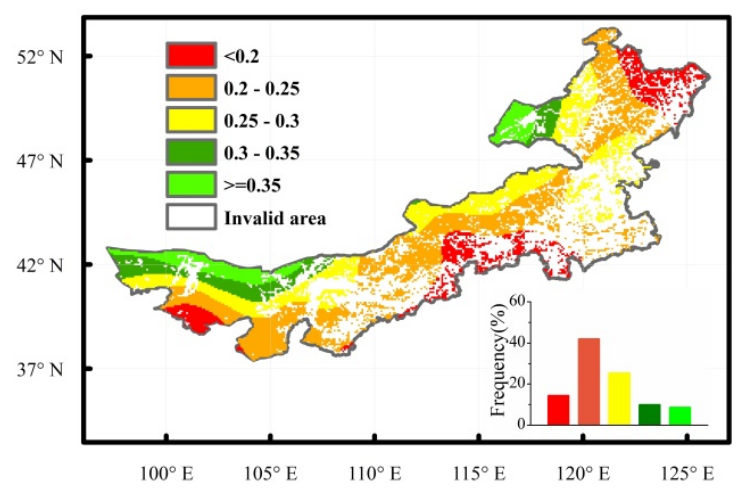

(c)

Figure 2. Spatial distributions of the coefficient of variation (CV) of the growing season normalized difference vegetation index (NDVI) (a), temperature (b), and precipitation (c) in Inner Mongolia during 1982-2015. The insets show the frequency distributions of the corresponding CV values.

At the biome scale, the $\mathrm{CV}$ values of the growing season NDVI show large variations among the six vegetation types (Figure 3a). The lowest variation occurred in the forest biome $(0.037)$, whereas the average growing season CV value was 0.044 for desert, 0.067 for meadow steppe, 0.095 for typical steppe, 0.096 for desert steppe, and 0.072 for crop. These findings indicate that typical steppe and desert steppe were less stable than the other biomes. Additionally, the temperature showed fluctuation trends nearly opposite to those of the growing season NDVI across all biomes except for desert and crop (Figure $3 \mathrm{~b}$ ). The maximum CV value for the growing season precipitation was 0.28 for desert and the minimum was 0.22 for forest and crop, which were much higher than the corresponding values for NDVI and temperature (Figure 3c).

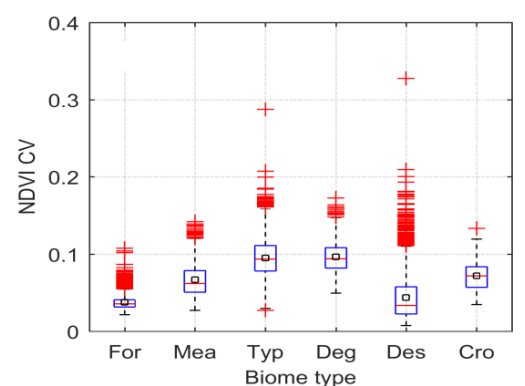

(a)

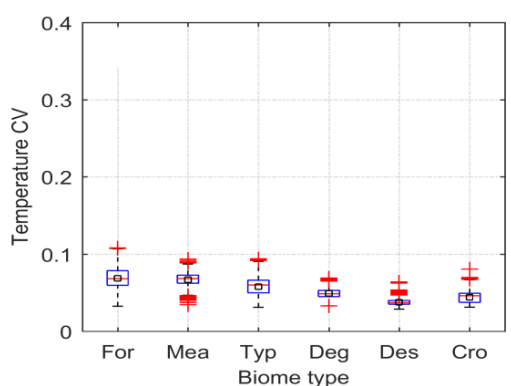

(b)

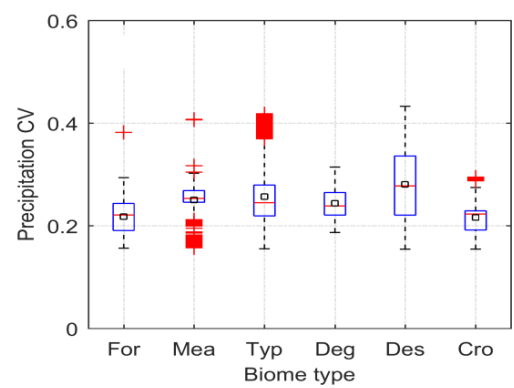

(c)

Figure 3. Mean CV of the growing season NDVI (a), temperature (b), and precipitation (c) for forest (For), meadow steppe (Mea), typical steppe (Typ), desert steppe (Deg), desert (Des), and crop (Cro) in Inner Mongolia during 1982-2015. The bottom and top edges of each blue box represent the 25th and 75th percentiles, respectively. The horizontal red line in each blue box indicates the median values. The open black square in each blue box means mean values. The black whiskers extend to the 1.5 times the interquartile range. Red crosses represent outliers. 


\subsubsection{Variability by Month}

There were considerable differences in the monthly CV values of NDVI for different biomes (Figure 4). The CV values for NDVI in forest and meadow steppe were lower in July and August than in the other months, especially in the early and later times of the growing season, which indicates that these biomes were more stable in the summer time. In contrast, for the typical steppe, desert steppe, and desert, the CV values of the NDVI were generally lower in spring and higher in summer. The CV value was highest in June and July for the typical steppe, and July and August for the desert steppe, and August and September for the desert, indicating an obvious time gradient across these biomes. Of all the biomes, the desert biome exhibited a more obvious spatial heterogeneity of the CV value, whereas there was quite high spatial consistency in crop. Additionally, the results of the correlation analysis demonstrated that the $\mathrm{CV}$ values of the growing season NDVI were most closely related to that of the NDVI in August for the forest, meadow steppe, typical steppe, and crop biomes, while in September for the desert and desert steppe biomes.

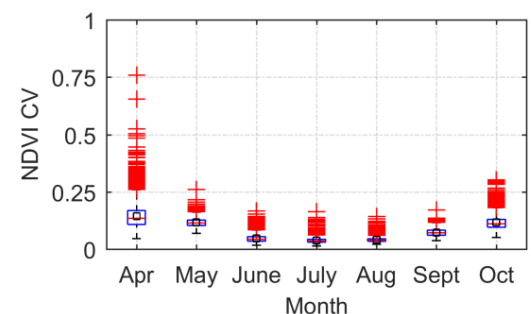

(a)

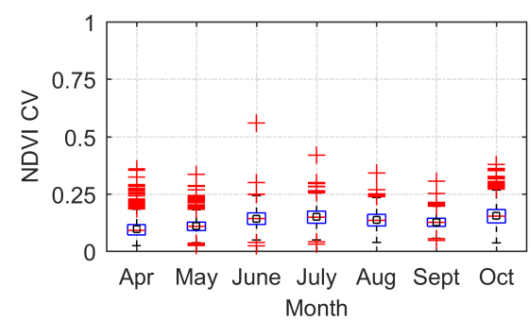

(c)

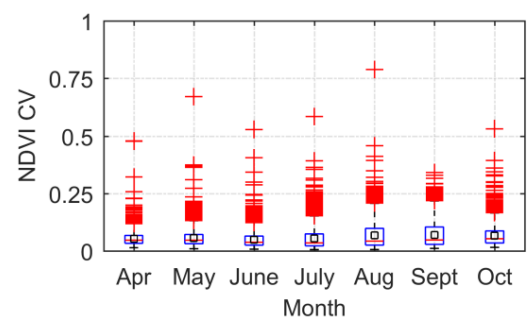

(e)

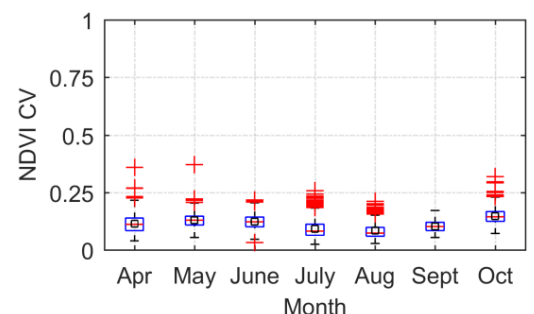

(b)

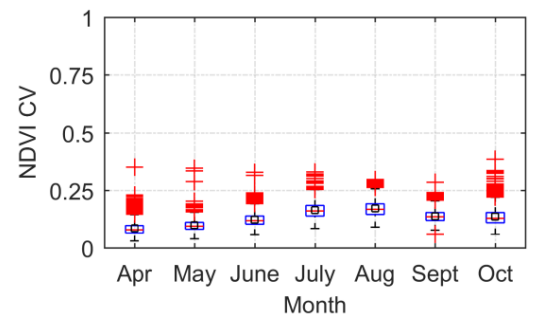

(d)

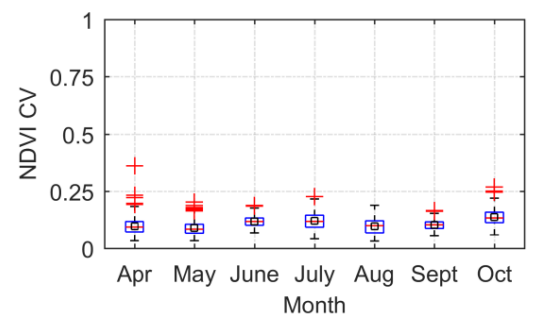

(f)

Figure 4. Mean CV of the monthly NDVI during the growing season for the (a) forest, (b) meadow, (c) typical steppe, (d) desert steppe, (e) desert, and (f) crop biomes in Inner Mongolia from 1982 to 2015. The bottom and top edges of each blue box represent the 25th and 75th percentiles, respectively. The horizontal red line in each blue box indicates the median values. The open black square in each blue box means mean values. The black whiskers extend to the 1.5 times the interquartile range. Red crosses represent outliers.

\subsection{Spatial Relationships between the NDVI Variability and Those of Temperature and Precipitation}

\subsubsection{Correlation in the Growing Season}

The relationship between variation in the growing season NDVI and variation in temperature differed greatly among the biomes (Figure 5). For the forest and steppe biomes, the CVs of the growing 
season NDVI were significantly related to those of temperature, with a linear slope less than 1 . That is, the CV of the growing season NDVI is a smaller proportion of the CV of the growing season temperature in regions where the $\mathrm{CV}$ of the growing season temperature is larger compared with regions in which the CV of the growing season temperature is small. This indicates that these ecosystems have the capacity to buffer temperature variability (Figure 5a). In addition, slopes for the meadow and forest were significantly less than those for the typical steppe and desert steppe, indicating that the buffering capacity of these two biomes is greater than that of the other biomes. In contrast, the desert tends to amplify temperature variations, with a slope value of 1.18 (Figure 5e). There was no relationship between the variation CVs of the growing season NDVI and the temperature for crop (Figure 5f). At the regional scales, no significant relationships were detected between variations in the growing season NDVI and variations in temperature. That is, variations in temperature may not be a useful predictor of variation patterns in the growing season NDVI across the six biomes. The geographical detector showed that the explanatory power of the temperature variations to the spatial distribution of the CVs of the growing season NDVI in Inner Mongolia was 13.15\%, with a significant difference among biomes. The power of the variations in temperature for determining the CVs of the growing season NDVI was larger for the meadow steppe and desert steppe, and smaller for crop (Figure 6a), which is in accordance with the result of Figure 5. Spatially, the regression coefficients from the GWR model demonstrated that the relationship between the CVs of the growing season NDVI and those of the temperature varied spatially, and is positive for most parts of the forest, typical steppe, desert steppe, and desert, whereas negative for most regions for the crop and meadow steppe (Figure 6b). These results are also consistent with the above linear regression analysis.
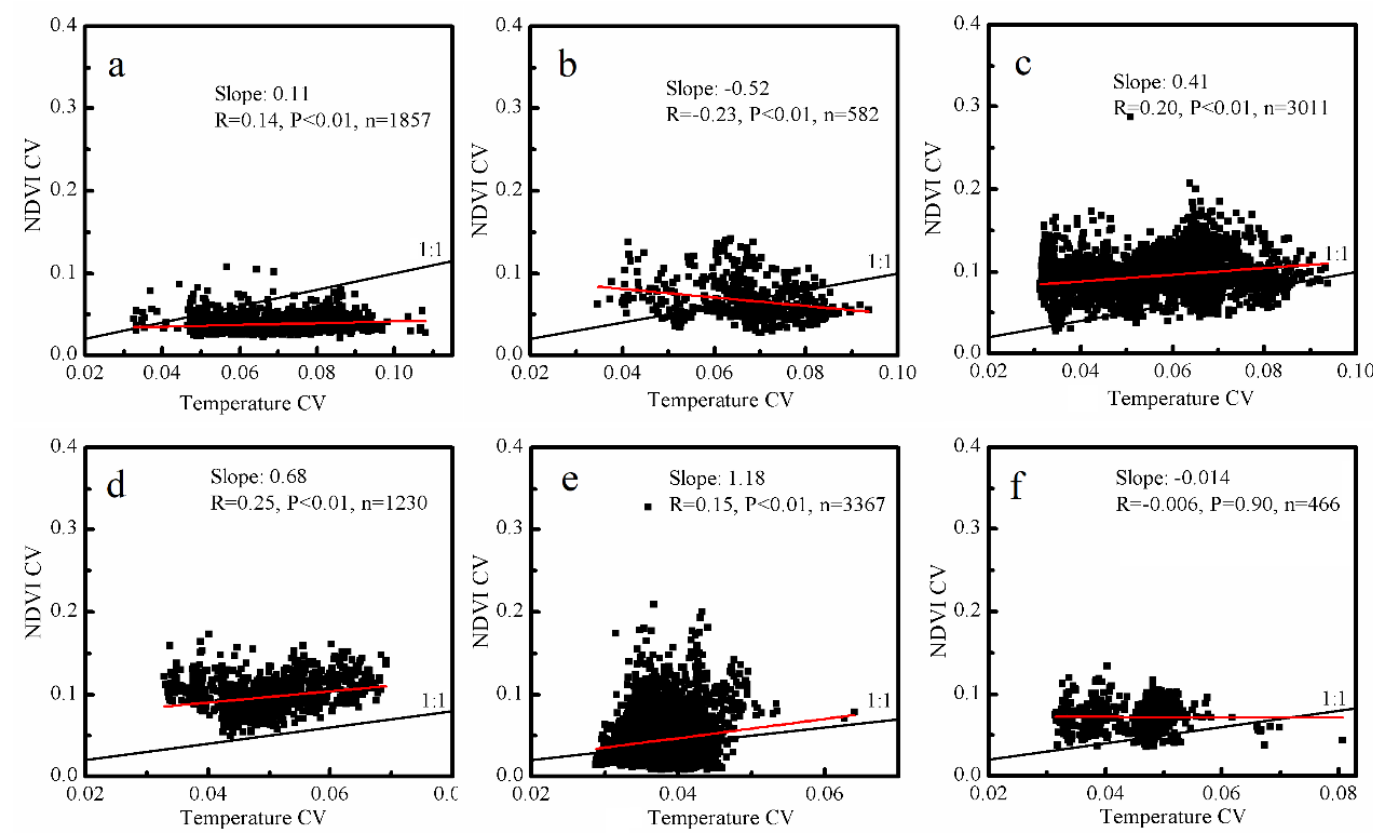

Figure 5. Relationships between the CVs of the growing season temperature and those of the NDVI in Inner Mongolia during 1982-2015: (a) forest, (b) meadow steppe, (c) typical steppe, (d) desert steppe, (e) desert, and (f) crop.

The CVs of the growing season NDVI were significantly related to those of precipitation for all biomes (Figure 7). For the three steppe biomes, the CVs of the growing season NDVI were positively correlated with those of precipitation $(R=0.18$ for meadow steppe, $R=0.38$ for typical steppe, $R=$ 0.27 for desert steppe; the slopes of the relationships for the different vegetation types were $0.13,0.16$, and 0.17 , respectively; Figure $7 \mathrm{~b}-\mathrm{d}$ ). These correlations imply that, although the CVs of vegetation in arid or semi-arid regions may increase with increasing variations in precipitation, the ratio of the variability in NDVI to that of the growing season precipitation will be lower. In contrast, an opposite 
relationship between the CVs of the growing season NDVI and those of precipitation occurred in the forest, desert, and crop biomes. That is, the CVs of vegetation tend to decrease with increasing variations in precipitation (Figure 7a,e,f). This implies that the buffering capacity of these biomes is sufficiently large to respond to variations in precipitation. In addition, the magnitude of the growing season NDVI variation was slightly smaller than that of precipitation, indicating that all of these vegetation types are more stable than precipitation fluctuation. At the regional scales, no significant relationships were detected between the variations in the CVs of the growing season NDVI and those of precipitation. Based on the geographical detector method, the explanatory power of the precipitation variations on the CVs of NDVI was higher than $10 \%$ for the crop, desert steppe, and meadow steppe, with the highest in the typical steppe (Figure 8a). Similar to the result from the linear regression, the GWR model exhibited that the CVs of the growing season NDVI were negatively related to those of precipitation in the forest and most parts of the desert, whereas they were positively related in most parts of the meadow steppe, typical steppe, and desert steppe (Figure $8 b$ ).

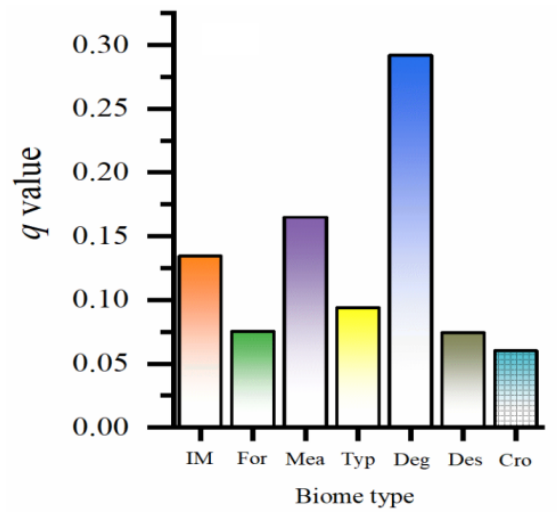

(a)

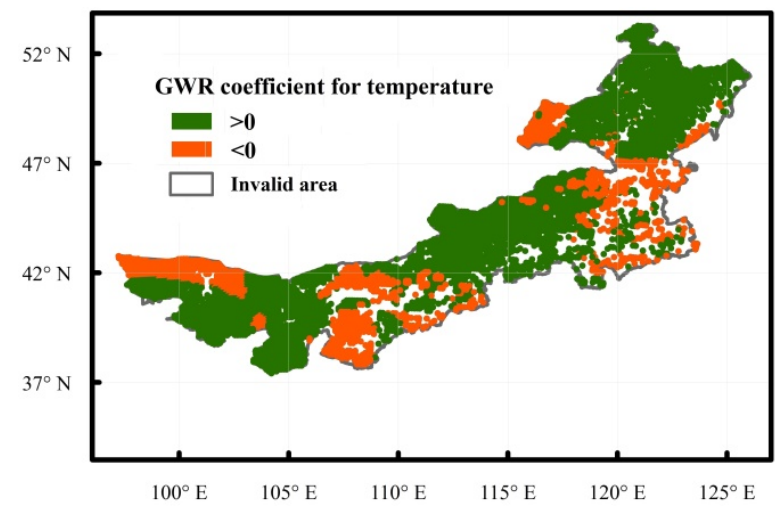

(b)

Figure 6. The power of temperature variation for determining the CVs of the growing season NDVI from the geographical detector (a) and regression coefficient between CVs of the growing season NDVI and those of temperature from geographically weighted regression (GWR) (b) during 1982-2015.
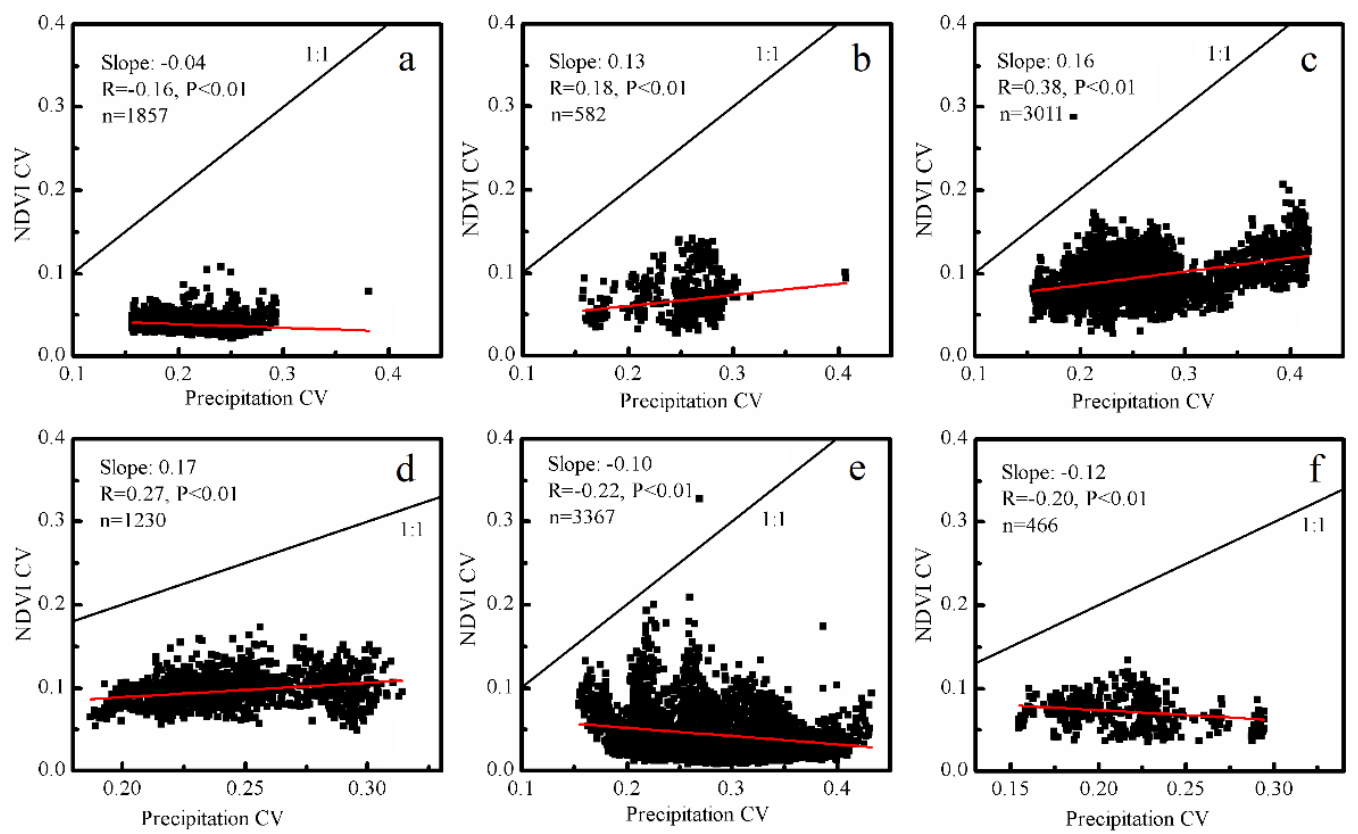

Figure 7. Relationships between the CVs of the growing season precipitation and those of the NDVI in Inner Mongolia during 1982-2015: (a) forest, (b) meadow steppe, (c) typical steppe, (d) desert steppe, (e) desert, and (f) crop. 


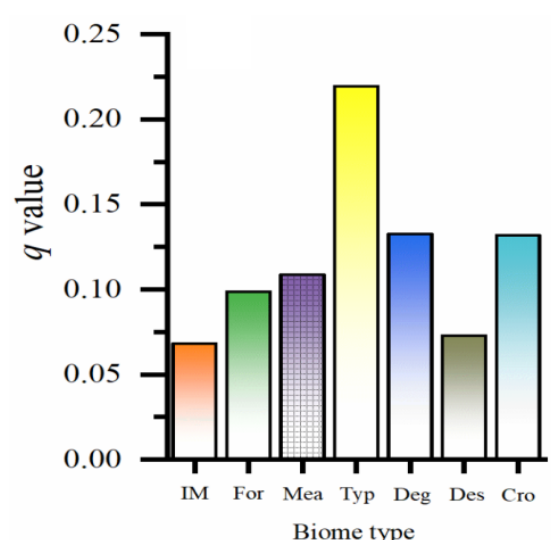

(a)

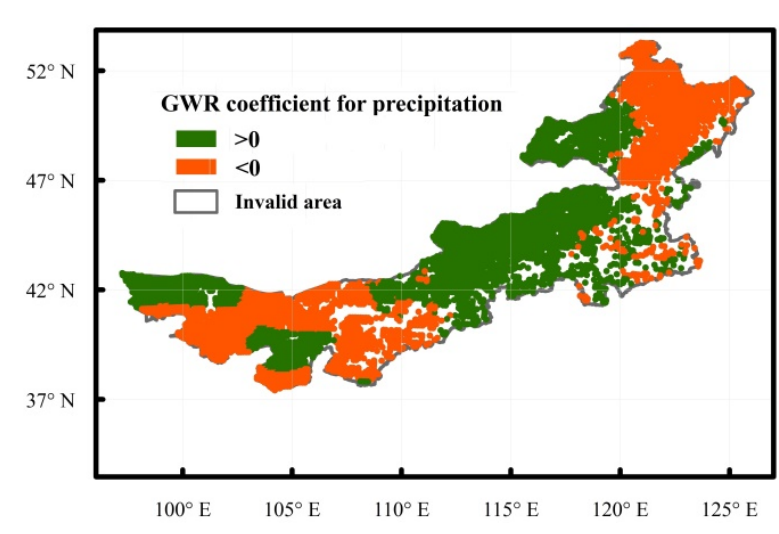

(b)

Figure 8. The power of precipitation variation for determining the CVs of the growing season NDVI from the geographical detector (a) and regression coefficient between CVs of the growing season NDVI and those of precipitation from GWR (b) during 1982-2015.

\subsubsection{Relationship by Month}

As demonstrated in Table 1, the CVs of the monthly NDVI for the forest were significantly negatively related to the CVs of temperature in April and June, while the relationships became positive in May and August-October, with the largest determinant coefficient in September. Similar patterns were found for the meadow steppe, except for June, July, and October. By contrast, there were positive relationships between the CVs of the monthly NDVI and those of temperature for all months across the growing season for the typical steppe. Additionally, positive correlations between the CVs of temperature and those of NDVI occurred in most months for the desert steppe (except for April and August), crop (except for April and October), and desert (except for May, July, and October). Interestingly, the linear slope values were not always lower than 1, especially in August for the typical steppe, desert, and crop, indicating that these ecosystem can amplify the temperature variations in summer time.

The relationships between the CVs of monthly NDVI and those of precipitation are shown in Table 2. In particular, there were negative correlations between the CVs of precipitation and those of NDVI in all months for the desert and months except in July for the forest. For the steppes, the CVs of the monthly NDVI were positively related to the CVs of precipitation in July and August for the meadow steppe; May, July, and August for the typical steppe; and May and July to October for the desert steppe, with negative or insignificant relations for other months. Additionally, for crop, the relationship was more complicated: Positive correlations in May, June, and September, and negative relationships in July and August. All of the biomes tend to have a capacity to buffer precipitation variability. 
Table 1. Relationships between the CVs of monthly temperature and those of the NDVI for different biomes in Inner Mongolia from 1982 to 2015.

\begin{tabular}{|c|c|c|c|c|c|c|c|c|c|c|c|c|c|c|}
\hline \multirow{2}{*}{ Vegetation Type } & \multicolumn{2}{|c|}{ April } & \multicolumn{2}{|c|}{ May } & \multicolumn{2}{|c|}{ June } & \multicolumn{2}{|c|}{ July } & \multicolumn{2}{|c|}{ August } & \multicolumn{2}{|c|}{ September } & \multicolumn{2}{|c|}{ October } \\
\hline & Slope & $\mathbf{R}$ & Slope & $\mathbf{R}$ & Slope & $\mathbf{R}$ & Slope & $\mathbf{R}$ & Slope & $\mathbf{R}$ & Slope & $\mathbf{R}$ & Slope & $\mathbf{R}$ \\
\hline Forest & -0.00 & $-0.54^{* *}$ & 0.09 & $0.14^{* *}$ & -0.29 & $-0.17^{* *}$ & -0.02 & -0.01 & 0.24 & 0.20 ** & 0.28 & $0.58 * *$ & 0.00 & 0.06 * \\
\hline Meadow steppe & -0.00 & $-0.19^{* *}$ & 0.82 & $0.56^{* *}$ & -0.14 & -0.05 & 1.87 & $0.32 * *$ & 0.29 & $0.08^{*}$ & 0.15 & $0.15^{* *}$ & 0.00 & 0.06 \\
\hline Typical steppe & 0.03 & $0.37^{* *}$ & 0.49 & $0.37^{* *}$ & 1.14 & $0.62 * *$ & 0.73 & $0.21^{* *}$ & 1.16 & $0.32^{* *}$ & 0.26 & $0.23^{* *}$ & 0.00 & 0.12 ** \\
\hline Desert steppe & 0.01 & 0.02 & 0.57 & $0.24 * *$ & 0.78 & $0.27^{* *}$ & 0.80 & $0.21 * *$ & 0.12 & 0.02 & 0.15 & $0.06^{*}$ & 0.12 & $0.27^{* *}$ \\
\hline Desert & 0.14 & $0.12^{* *}$ & -0.33 & $-0.06^{* *}$ & 0.82 & $0.13 * *$ & -0.13 & -0.01 & 7.34 & $0.56^{* *}$ & 3.70 & $0.33^{* *}$ & 0.04 & 0.03 \\
\hline Crop & 0.00 & 0.01 & 0.44 & $0.21^{* *}$ & 0.29 & $0.15^{* *}$ & 1.33 & $0.23^{* *}$ & 1.65 & $0.53^{* *}$ & 0.34 & $0.28^{* *}$ & 0.00 & 0.02 \\
\hline
\end{tabular}

Table 2. Relationships between the CVs of monthly precipitation and those of the NDVI for different biomes in Inner Mongolia from 1982 to 2015.

\begin{tabular}{|c|c|c|c|c|c|c|c|c|c|c|c|c|c|c|}
\hline \multirow{2}{*}{ Vegetation Type } & \multicolumn{2}{|c|}{ April } & \multicolumn{2}{|c|}{ May } & \multicolumn{2}{|c|}{ June } & \multicolumn{2}{|c|}{ July } & \multicolumn{2}{|c|}{ August } & \multicolumn{2}{|c|}{ September } & \multicolumn{2}{|c|}{ October } \\
\hline & Slope & $\mathbf{R}$ & Slope & $\mathbf{R}$ & Slope & $\mathbf{R}$ & Slope & $\mathbf{R}$ & Slope & $\mathbf{R}$ & Slope & $\mathbf{R}$ & Slope & $\mathbf{R}$ \\
\hline Forest & -0.33 & $-0.57 * *$ & -0.10 & $-0.24^{* *}$ & -0.08 & $-0.18^{* *}$ & 0.05 & $0.19 * *$ & -0.02 & $-0.11^{* *}$ & -0.10 & $-0.28^{* *}$ & -0.06 & $-0.12^{* *}$ \\
\hline Meadow steppe & -0.08 & $-0.28^{* *}$ & 0.04 & 0.08 & -0.03 & -0.04 & 0.55 & $0.59 * *$ & 0.21 & $0.27 * *$ & -0.05 & $-0.14^{* *}$ & 0.00 & 0.01 \\
\hline Typical steppe & -0.04 & $-0.15 * *$ & 0.07 & $0.17^{* *}$ & -0.07 & $-0.13^{* *}$ & 0.32 & $0.49^{* *}$ & 0.15 & $0.27 * *$ & -0.03 & $-0.08 * *$ & -0.01 & -0.02 \\
\hline Desert steppe & 0.04 & $-0.20^{* *}$ & 0.05 & $0.21^{* *}$ & 0.01 & 0.05 & 0.23 & $0.42 * *$ & 0.24 & $0.42 * *$ & 0.18 & $0.29^{* *}$ & 0.07 & $0.27^{* *}$ \\
\hline Desert & -0.02 & $-0.19 * *$ & -0.05 & $-0.30^{* *}$ & -0.14 & $-0.24^{* *}$ & -0.17 & $-0.37^{* *}$ & -0.15 & $-0.41^{* *}$ & -0.13 & $-0.57^{* *}$ & -0.03 & $-0.26^{* *}$ \\
\hline Crop & 0.03 & 0.08 & 0.06 & $0.16^{* *}$ & 0.12 & $0.22^{* *}$ & -0.18 & $-0.22^{* *}$ & -0.21 & $-0.36^{* *}$ & -0.07 & $0.32^{* *}$ & -0.03 & -0.08 \\
\hline
\end{tabular}

** and * means the significance level $p<0.01$ and $p<0.05$. 


\subsection{Lagged Effect of Climate Change}

The relationships between the CVs of monthly NDVI and those of temperature in the previous month were stronger than those without considering the time lag effects for most biomes (except for desert steppe) in the later period of the growing season (Table 3). For example, in September and October, the $R$ values with one month lag were 0.65 and 0.19 for forest, 0.44 and 0.28 for meadow steppe, 0.34 and 0.38 for typical steppe, 0.56 and 0.32 for desert, and 0.48 and 0.24 for crop, which are larger than those without considering the time lag effects. In comparison, the relationship between the CVs of the monthly NDVI and those of precipitation in the previous month was more complicated, differing among the specific months of the growing season and biome types, especially for the steppes and desert (Table 4). At the growing season scale, the CVs of the growing season NDVI were significantly associated with those of the March-September temperatures and precipitations, similar to that between the CVs of NDVI and those of climate variables during the growing season for all biomes except for crop (Table 5).

Table 3. Correlations between the CVs of monthly NDVI and those of the temperature in the previous month for different biomes in Inner Mongolia from 1982 to 2015.

\begin{tabular}{|c|c|c|c|c|c|c|c|}
\hline \multirow{2}{*}{ Vegetation Type } & \multicolumn{7}{|c|}{ Correlation Coefficient (R) } \\
\hline & April & May & June & July & August & September & October \\
\hline Forest & $0.21 * *$ & $0.06^{*}$ & $-0.26 * *$ & $-0.24 * *$ & 0.05 & $0.65 * *$ & $0.19 * *$ \\
\hline Meadow steppe & $0.22 * *$ & 0.16 ** & $-0.17 * *$ & $-0.45 * *$ & $-0.32 * *$ & $0.44 * *$ & $0.28 * *$ \\
\hline Typical steppe & 0.01 & $0.27 * *$ & $0.56^{* *}$ & $0.13^{* *}$ & $0.13^{* *}$ & $0.34^{* *}$ & $0.38^{* *}$ \\
\hline Desert steppe & 0.03 & $0.29 * *$ & $0.30 * *$ & $0.23 * *$ & $0.16 * *$ & 0.01 & $0.22 * *$ \\
\hline Desert & 0.02 & $0.12 * *$ & $-0.04 *$ & $0.10 * *$ & 0.01 & $0.56 * *$ & $0.32 * *$ \\
\hline Crop & 0.06 & $0.21^{* *}$ & $0.14^{* *}$ & $-0.36^{* *}$ & $0.32 * *$ & $0.48^{* *}$ & $-0.24 * *$ \\
\hline
\end{tabular}

** and * means the significance level $p<0.01$ and $p<0.05$. Bolded black numbers denote larger correlation coefficients between the monthly mean NDVI and the corresponding climate variables in the preceding month, compared with those for climate variables in the same month. Bolded red numbers denote an opposite correlation between the monthly mean NDVI and the corresponding climate variables in the preceding month, compared with those for climate variables in the same month.

Table 4. Correlations between the CVs of monthly NDVI and those of the precipitation in the previous month for different biomes in Inner Mongolia from 1982 to 2015.

\begin{tabular}{|c|c|c|c|c|c|c|c|}
\hline \multirow{2}{*}{ Vegetation Type } & \multicolumn{7}{|c|}{ Correlation Coefficient } \\
\hline & April & May & June & July & August & September & October \\
\hline Forest & $-0.12 * *$ & $-0.14 * *$ & $0.11 * *$ & 0.02 & $-0.09 * *$ & $-0.25^{* *}$ & -0.05 \\
\hline Meadow steppe & $-0.11 *$ & $-0.35^{* *}$ & $0.31 * *$ & -0.07 & $0.55^{* *}$ & $0.16 * *$ & $-0.34 * *$ \\
\hline Typical steppe & $0.19 * *$ & $-0.14^{* *}$ & $0.38 * *$ & 0.04 & $0.43 * *$ & $0.36 * *$ & $-0.19 * *$ \\
\hline Desert steppe & $0.35^{* *}$ & $0.20^{* *}$ & $0.22 * *$ & -0.04 & $0.34^{* *}$ & $0.33^{* *}$ & $0.31 * *$ \\
\hline Desert & $-0.36 * *$ & $-0.24 * *$ & $-0.31 * *$ & $-0.19 * *$ & $-0.41^{* *}$ & $-0.45^{* *}$ & $-0.38 * *$ \\
\hline Crop & -0.04 & $-0.26 * *$ & $0.12^{* *}$ & -0.07 & $-0.23^{* *}$ & $-0.40 * *$ & 0.01 \\
\hline
\end{tabular}

** and * means the significance level $p<0.01$ and $p<0.05$. Bolded black numbers denote larger correlation coefficients between the monthly mean NDVI and the corresponding climate variables in the preceding month, compared with those for climate variables in the same month. Bolded red numbers denote an opposite correlation between the monthly mean NDVI and the corresponding climate variables in the preceding month, compared with those for climate variables in the same month.

Table 5. Correlations between the CVs of growing season NDVI and those of climate variables during March-September for different biomes in Inner Mongolia from 1982 to 2015.

\begin{tabular}{|c|c|c|c|c|c|c|}
\hline \multirow{2}{*}{$\begin{array}{c}\text { Vegetation } \\
\text { Type }\end{array}$} & \multicolumn{6}{|c|}{ Correlation Coefficient } \\
\hline & Forest & Meadow Steppe & Typical Steppe & Desert Steppe & Desert & Crop \\
\hline Precipitation & $-0.11 * *$ & $0.25 * *$ & $0.41 * *$ & $0.27 * *$ & $-0.28 * *$ & $0.14^{* *}$ \\
\hline Temperature & $0.19 * *$ & $-0.24 * *$ & $0.18^{* *}$ & $0.25^{* *}$ & $0.25 * *$ & -0.03 \\
\hline
\end{tabular}

** and * means the significance level $p<0.01$ and $p<0.05$. Bolded black numbers denote larger correlation coefficients between the monthly mean NDVI and the corresponding climate variables in the preceding month, compared with those for climate variables in the same month. 


\section{Discussion}

\subsection{Variability Patterns of NDVI for Vegetation Biomes}

Evidence from previous observational studies indicates that the largest $\mathrm{CVs}$ of annual aboveground net primary productivity (ANPP) are in grassland biomes, followed by that in crop and desert biomes, whereas the CVs of annual ANPP in forest biomes are distinctly smaller than those for other vegetation types [6]. These patterns are consistent with the results of the present study. However, the CVs of the growing season NDVI in our study are about half of those found in another study [6] and about half of the $\mathrm{CV}$ values for corresponding steppes in Inner Mongolia as determined by direct measurements of annual ANPP [28]. This discrepancy could be attributed to differences in the spatial scales of ANPP measurements obtained by direct measurement versus those inferred from NDVI. For instance, species composition, frequency, and abundance of key species may be the main factor determining vegetation variations at the site level $[28,29]$, whereas vegetation variations could be mainly related to the compositions of plant communities at a large scale [30]. It is well known that ecosystem stability progressively increases as increases in the hierarchy of organizational levels due to compensatory interactions among major components of the ecosystem [31,32]. An increase in sample size is often associated with a reduction in variance of the variable being measured [33]. In addition, a study based on annual NDVI data during the period 1982-1999 across biomes in China showed that the largest variability of the NDVI occurs in the desert biome, followed by variability for herbaceous vegetation and for the forest biome [12]. These differences can perhaps be attributed to the extent of spatial coverage of the two studies and to the fact that in the present study, biases associated with land use changes were removed from the data set.

\subsection{Correlations between NDVI Variability and Climate Change}

The CVs of the growing season NDVI are significantly associated with interannual variations in corresponding temperatures and precipitations at the biome scale. These findings are generally consistent with those of previous studies at biome scales [12,33]. In this study, however, we did not observe a relationship between the CVs of the growing season NDVI and those of temperature and precipitation at regional scales, as was observed in the study across the whole of China [12]. However, the results of this study are consistent with those of Knapp and Smith [6], who also did not find a relationship between interannual variations in precipitation and those in ANPP across biomes in North America. Numerous studies have suggested that terrestrial ecosystems exhibit complex behaviors in response to climate change, and that responses vary significantly among different vegetation types $[27,34]$. Variations in temperate and boreal vegetation tend to be positively correlated with present-day temperature anomalies. In contrast, tropical and arid ecosystems often show negative correlations between those temperature and vegetation variations [35].

In this study, patterns of correlation between the CV of the NDVI and that of precipitation and temperature differ dramatically among biomes at the growing season scale. The forest biome (a temperate humid or sub-humid ecosystem) shows a positive correlation of the $\mathrm{CV}$ of the growing season NDVI with that of the growing season temperature, but a negative correlation with that of the growing season precipitation. Forest in this region is always located in areas with relatively abundant rainfall and low temperatures, where temperature is the dominant limiting factor on growth (rather than precipitation); thus, vegetation activity always responds positively to temperature anomalies [36,37]. However, a large increase in the amount of rainfall can increase humidity and cloudiness, which can lower temperatures and reduce solar radiation $[37,38]$. Such factors may decrease forest growth during wet years, which can perhaps offset the positive effects of precipitation on vegetation, thus leading to a minor change in biome productivity. In contrast, steppe (temperate semi-arid ecosystems) shows opposite patterns between the CV of the NDVI and that of precipitation as those of forest. In steppes, precipitation is a key factor for grass growth, suggesting that the growing season NDVI responds directly to rainfall anomalies $[39,40]$. From the meadow steppe to the desert steppe, the response of 
grass to precipitation variation may be much stronger due to an increased moisture deficit. Meanwhile, the potential effects of extreme temperature on grass growth could be more severe in drier areas because of the induced evapotranspiration demand [41,42]. In addition, in arid ecosystems (desert biomes), water stress severely limits vegetation growth. Rainfall events can promote the growth of many ephemeral species, known as blooming events in deserts [43]. However, anomalously rising or falling temperatures can cause dramatic variations in moisture deficits, thus resulting in devastating damage or compensatory growth, respectively; this may explain why the CVs of the growing season NDVI for desert biomes are positively related to interannual variabilities in temperature, and why deserts tend to amplify temperature variations. Crop biomes are mainly artificial ecosystems in which humans play a critical role in regulating vegetation function, and the mechanisms that underlie a negative relationship between the CVs of the growing season NDVI and those of climate variables require further study. It has been widely reported that a lagged vegetation response to climate change may exist, but the length of the lag time is likely to vary spatially and temporally $[35,37,44]$. For example, Braswell et al. reported that NDVI had a 2-year lagged response to temperature [35]. Piao et al. suggested the lag time to temperature and precipitation was approximately three months [44]. Our results show that the a one-month lagged response of NDVI to climate changes was significant at both the growing season scale and the monthly scale, affirming the importance of considering the time lag effects in investigating the NDVI response to climate changes.

\subsection{Uncertainties}

In this study, we calculated the relationships between the CVs of the growing season NDVI and those of temperature and precipitation for each biome in Inner Mongolia, after minimizing the impacts from land use changes. However, uncertainties remain from the definition of the growing season length. Observation-based studies have shown that the growing season would vary in length depending on the species, biome regions, and climate change across Inner Mongolia [45,46], despite the period from April to October being regarded as the growing season by several studies [47]. However, due to the limitations of the phenological observations, it is difficult to gain the whole species-averaged growing season information at the regional scale. Accurate assessment of the growing season period for biomes is needed for further study in the future. In order to characterize these uncertainties, we calculated the thermal growing season, one of the main techniques to capture the growing season length at relatively larger spatial scales, based on the observed daily mean air temperature of 46 meteorological stations across Inner Mongolia. This was defined as the period from the first appearance of five consecutive days with the 5-day moving average daily temperature higher than $0{ }^{\circ} \mathrm{C}$ to the last appearance of five consecutive days with $\mathrm{T}>0{ }^{\circ} \mathrm{C}$ in autumn. The result showed that the mean onset of the growing season was the 82th day for the crop and grass region but the 97th for the forest area (Julian day), while the corresponding cessation dates were the 309th, 306th, and 292th day (Julian day), respectively. This confirmed that the definition of the growing season period from April to October was broadly reasonable. In addition, although we tried to eliminate the bias related to the effects of land use change on NDVI values, the pixels with no land use change only between the 1980s and 2000s could still result in some uncertainties.

On the other hand, spatial autocorrelation could also influence the results of correlation analyses. Several methods have been developed to correct the effects of spatial autocorrelation for spatial analysis, such as autocovariate regression, simultaneous autoregressive models, conditional autoregressive models, and so on [48-50], but these models are complicated and sensitive to the model set-up, such as the model structure, neighborhood distance, and coding styles of spatial weights matrices [51]. Additionally, these methods assume spatial stationarity and isotropic spatial autocorrelation [52]. Nevertheless, under actual geographical conditions, anisotropic spatial autocorrelation and non-stationarity in spatial patterns may appear [53]. It would be expected that spatial regression may not be very robust to violations of this assumption. Thus, although spatial autocorrelation models have been known for decades in the statistical literature, their application in the ecological literature has been limited up to 
now [54]. Further investigation of the effect of spatial autocorrelation is clearly a question deserving future research.

\section{Conclusions}

Based on the latest updated GIMMS NDVI data from 1982-2015, we explored the interannual variability in NDVI for different biomes in Inner Mongolia and their responses to climatic factors. The results demonstrated that the CVs of the growing season NDVI were most variable for desert steppe and typical steppe, followed by crop and meadow steppe, desert, and forest. In addition, the desert biome exhibited a more obvious spatial heterogeneity of the $\mathrm{CV}$ value, whereas there was quite high spatial consistency in crop, which may be related to the agriculture management. Interannual variations of NDVI during the growing season were generally related to those of the corresponding temperature and precipitation at the biome scales, and even most closely related to those of previous months, indicating a strong one-month lagged response of NDVI variation to climate variables. However, the correlations differed dramatically among biomes and months, exhibiting unique biome-dependent responses. Additionally, the slopes of the linear regression between variations in the growing season NDVI and those of climate variables for steppes, crop, and forest were less than 1 , indicating that the biomes have a capacity to buffer climate variable fluctuations, whereas desert tends to amplify the variation in temperature. Many mechanisms may account for the buffer response of vegetation to climate variability, such as plant physiological adjustments [55], transfer of soil water from one month or one season to the next, mineral nutrient supply [56], and compensatory interactions among major components at both the species and functional group levels [28]. These findings are of importance to support the development of improved management strategies.

Author Contributions: Conceptualization, L.G., J.G. and S.M.; Methodology \& Software, L.Z., Y.J. and L.G.; Formal Analysis, L.Z., Y.J. and L.G.; Writing-Original Draft Preparation, L.G., J.G. and Y.Z.; Writing-Review \& Editing, L.G., Y.Z. and S.W.; Supervision, L.G., J.G., Y.Z. and S.W. All authors have read and agreed to the published version of the manuscript.

Funding: This study was supported by the Natural Science Foundation of China (No. 41601580, 41671098, U1904210), National Key Research and Development Program of China (No. 2017YFD0301106-1, 2018YFC1508900, 2018YFC1508801), Research Projects of Land and Resources in Henan Province (No. 20190450-7), Innovative Research Team of Henan Polytechnic University (No. T2018-4), and Doctor Foundation of Henan University of Technology (No. B2015-22).

Acknowledgments: We thank the journal editor and the anonymous reviewers for their useful comments and great efforts on this paper.

Conflicts of Interest: The authors declare no conflict of interest.

\section{References}

1. Lemordant, L.; Gentine, P.; Swann, A.S.; Cook, B.I.; Scheff, J. Critical impact of vegetation physiology on the continental hydrologic cycle in response to increasing $\mathrm{CO}_{2}$. Proc. Natl. Acad. Sci. USA 2018, 115, 4093-4098. [CrossRef]

2. Yuan, W.; Piao, S.; Qin, D.; Dong, W.; Xia, J.; Lin, H.; Chen, M. Influence of Vegetation Growth on the Enhanced Seasonality of Atmospheric $\mathrm{CO}_{2}$. Glob. Biogeochem. Cycles 2018, 32, 32-41. [CrossRef]

3. Gao, J.; Jiao, K.; Wu, S.; Ma, D.; Zhao, D.; Yin, Y.; Dai, E. Past and future effects of climate change on spatially heterogeneous vegetation activity in China. Earth's Future 2017, 5, 679-692. [CrossRef]

4. Ding, Y.; Xu, J.; Wang, X.; Peng, X.; Cai, H. Spatial and temporal effects of drought on Chinese vegetation under different coverage levels. Sci. Total Environ. 2020, 716, 137166. [CrossRef] [PubMed]

5. Zscheischler, J.; Michalak, A.M.; Schwalm, C.; Mahecha, M.D.; Huntzinger, D.N.; Reichstein, M.; Berthier, G.; Ciais, P.; Cook, R.B.; El-Masri, B. Impact of large-scale climate extremes on biospheric carbon fluxes: An intercomparison based on MsTMIP data. Glob. Biogeochem. Cycles 2014, 28, 585-600. [CrossRef]

6. Knapp, A.K.; Smith, M.D. Variation among biomes in temporal dynamics of aboveground primary production. Science 2001, 291, 481-484. [CrossRef] [PubMed] 
7. Lu, Q.; Zhao, D.; Wu, S.; Dai, E.; Gao, J. Using the NDVI to analyze trends and stability of grassland vegetation cover in Inner Mongolia. Theor. Appl. Climatol. 2019, 135, 1629-1640. [CrossRef]

8. Ju, J.; Masek, J.G. The vegetation greenness trend in Canada and US Alaska from 1984-2012 Landsat data. Remote Sens. Environ. 2016, 176, 1-16. [CrossRef]

9. Zhao, L.; Dai, A.; Dong, B. Changes in global vegetation activity and its driving factors during 1982-2013. Agric. For. Meteorol. 2018, 249, 198-209. [CrossRef]

10. Guo, M.; Li, J.; He, H.; Xu, J.; Jin, Y. Detecting global vegetation changes using mann-kendal (MK) trend test for 1982-2015 time period. Chin. Geogr. Sci. 2018, 28, 907-919. [CrossRef]

11. Meng, M.; Huang, N.; Wu, M.; Pei, J.; Wang, J.; Niu, Z. Vegetation change in response to climate factors and human activities on the Mongolian Plateau. PeerJ 2019, 7, e7735. [CrossRef] [PubMed]

12. Fang, J.; Piao, S.; Tang, Z.; Peng, C.; Ji, W. Interannual variability in net primary production and precipitation. Science 2001, 293, 1723. [CrossRef] [PubMed]

13. De Keersmaecker, W.; Lhermitte, S.; Honnay, O.; Farifteh, J.; Somers, B.; Coppin, P. How to measure ecosystem stability? An evaluation of the reliability of stability metrics based on remote sensing time series across the major global ecosystems. Glob. Chang. Biol. 2014, 20, 2149-2161. [CrossRef] [PubMed]

14. Ray, D.K.; Gerber, J.S.; MacDonald, G.K.; West, P.C. Climate variation explains a third of global crop yield variability. Nat. Commun. 2015, 6, 5989. [CrossRef] [PubMed]

15. Sloat, L.L.; Gerber, J.S.; Samberg, L.H.; Smith, W.K.; Herrero, M.; Ferreira, L.G.; Godde, C.M.; West, P.C. Increasing importance of precipitation variability on global livestock grazing lands. Nat. Clim. Chang. 2018, 8, 214-218. [CrossRef]

16. Kawabata, A.; Ichii, K.; Yamaguchi, Y. Global monitoring of interannual changes in vegetation activities using NDVI and its relationships to temperature and precipitation. Int. J. Remote Sens. 2001, 22, 1377-1382. [CrossRef]

17. Lauenroth, W.; Sala, O.E. Long-term forage production of North American shortgrass steppe. Ecol. Appl. 1992, 2, 397-403. [CrossRef]

18. Wu, C.; Wang, L.; Niu, Z.; Gao, S.; Wu, M. Nondestructive estimation of canopy chlorophyll content using Hyperion and Landsat/TM images. Int. J. Remote Sens 2010, 31, 2159-2167. [CrossRef]

19. Hou, W.; Gao, J.; Wu, S.; Dai, E. Interannual variations in growing-season NDVI and its correlation with climate variables in the southwestern karst region of China. Remote Sens. 2015, 7, 11105-11124. [CrossRef]

20. Chu, H.; Venevsky, S.; Wu, C.; Wang, M. NDVI-based vegetation dynamics and its response to climate changes at Amur-Heilongjiang River Basin from 1982 to 2015. Sci. Total Environ. 2019, 650, 2051-2062. [CrossRef] [PubMed]

21. Brogaard, S.; Runnström, M.; Seaquist, J.W. Primary production of Inner Mongolia, China, between 1982 and 1999 estimated by a satellite data-driven light use efficiency model. Glob. Planet. Chang. 2005, 45, 313-332. [CrossRef]

22. Wu, S.; Yang, Q.; Zheng, D. Delineation of eco-geographic regional system of China. J. Geogr. Sci. 2003, 13, 309-315. [CrossRef]

23. Holben, B.N. Characteristics of maximum-value composite images from temporal AVHRR data. Int. J. Remote Sens. 1986, 7, 1417-1434. [CrossRef]

24. Wang, H.; Li, X.; Li, X.; Ying, G.; Fu, N. The variability of vegetation growing season in the northern China based on NOAA NDVI and MSAVI from 1982 to 1999. Acta Ecol. Sinica 2007, 27, 504-515. (In Chinese)

25. Tong, S.; Zhang, J.; Bao, Y. Spatial and temporal variations of vegetation cover and the relationships with climate factors in Inner Mongolia based on GIMMS NDVI3g data. J. Arid Land 2017, 9, 394-407. [CrossRef]

26. Department of animal husbandry and veterinary; General station of animal husbandry and veterinary of ministry of agriculture of China. Rangeland Resource of China 1996; China Science and Technology Press: Beijing, China, 1996. (In Chinese)

27. Jiao, K.; Gao, J.; Wu, S. Climatic determinants impacting the distribution of greenness in China: Regional differentiation and spatial variability. Int. J. Biometeorol. 2019, 63, 523-533. [CrossRef]

28. Bai, Y.; Han, X.; Wu, J.; Chen, Z.; Li, L. Ecosystem stability and compensatory effects in the Inner Mongolia grassland. Nature 2004, 431, 181-184. [CrossRef]

29. Su, F.; Wei, Y.; Wang, F.; Guo, J.; Zhang, J.; Wang, Y.; Guo, H.; Hu, S. Sensitivity of plant species to warming and altered precipitation dominates the community productivity in a semiarid grassland on the Loess Plateau. Ecol. Evol. 2019, 9, 7628-7638. [CrossRef] 
30. Wardle, D.A.; Bonner, K.I.; Barker, G.M. Stability of ecosystem properties in response to above-ground functional group richness and composition. Oikos 2000, 89, 11-23. [CrossRef]

31. Mcnaughton, S.J. Diversity and stability of ecological communities: A comment on the role of empiricism in ecology. Am. Nat. 1977, 111, 515-525. [CrossRef]

32. Brown, B.L.; Downing, A.L.; Leibold, M.A. Compensatory dynamics stabilize aggregate community properties in response to multiple types of perturbations. Ecology 2016, 97, 2021-2033. [CrossRef] [PubMed]

33. Paruelo, J.M.; Lauenroth, W.K. Interannual variability of NDVI and its relationship to climate for North American shrublands and grasslands. J. Biogeogr. 1998, 25, 721-733. [CrossRef]

34. Harte, J.; Shaw, R. Shifting Dominance Within a Montane Vegetation Community: Results of a ClimateWarming Experiment. Science 1995, 267, 876-880. [CrossRef] [PubMed]

35. Braswell, B.H.; Schimel, D.S.; Linder, E.; Moore III, B. The response of global terrestrial ecosystems to interannual temperature variability. Science 1997, 278, 870-873. [CrossRef]

36. Mao, D.; Wang, Z.; Luo, L.; Ren, C. Integrating AVHRR and MODIS data to monitor NDVI changes and their relationships with climatic parameters in Northeast China. Int. J. Appl. Earth Obs. Geoinf. 2012, 18, 528-536. [CrossRef]

37. Piao, S.; Fang, J.; Zhou, L.; Guo, Q.; Henderson, M.; Ji, W.; Li, Y.; Tao, S. Interannual variations of monthly and seasonal normalized difference vegetation index (NDVI) in China from 1982 to 1999. J. Geophys. Res. 2003, 108, 4401. [CrossRef]

38. Piao, S.; Fang, J.; Zhou, L.; Ciais, P.; Zhu, B. Variations in satellite-derived phenology in China's temperate vegetation. Glob. Chang. Biol. 2006, 12, 672-685. [CrossRef]

39. Zhang, G.; Xu, X.; Zhou, C.; Zhang, H.; Ouyang, H. Responses of grassland vegetation to climatic variations on different temporal scales in Hulun Buir Grassland in the past 30 years. J. Geogr. Sci. 2011, 21, 634-650. [CrossRef]

40. Nicholson, S.E.; Davenport, M.L.; Malo, A.R. A comparison of the vegetation response to rainfall in the Sahel and East Africa, using normalized difference vegetation index from NOAA AVHRR. Clim. Chang. 1990, 17, 209-241. [CrossRef]

41. Piao, S.; Friedlingstein, P.; Ciais, P.; Viovy, N.; Demarty, J. Growing season extension and its impact on terrestrial carbon cycle in the Northern Hemisphere over the past 2 decades. Glob. Biogeochem. Cycles 2007, 21, GB3018. [CrossRef]

42. Mu, S.; Yang, H.; Li, J.; Chen, Y.; Gang, C.; Zhou, W.; Ju, W. Spatio-temporal dynamics of vegetation coverage and its relationship with climate factors in Inner Mongolia, China. J. Geogr. Sci. 2013, 23, 231-246. [CrossRef]

43. Vidiella, P.E.; Armesto, J.J. Emergence of ephemeral plant species from soil samples of the Chilean coastal desert in response to experimental irrigation. Rev. Chil. de Hist. Nat. 1989, 62, 99-107.

44. Piao, S.; Mohammat, A.; Fang, J.; Cai, Q.; Feng, J. NDVI-based increase in growth of temperate grasslands and its responses to climate changes in China. Glob. Environ. Chang. 2006, 16, 340-348. [CrossRef]

45. Gu, R.; Zhou, W.; Bai, M.; Li, X.; Di, R.; Yang, J. Impacts of climate change on phenological phase of herb in the main grassland in Inner Mongolia. Acta Ecol. Sinnica 2011, 32, 767-776. (In Chinese) [CrossRef]

46. Yang, L.; Hou, Q. Phenological changes of populus simonii and its relationship with meteorological conditions in the Eastern Inner Mongolia. J. Meteorol. Environ. 2008, 22, 39-44. (In Chinese) [CrossRef]

47. Peng, S.; Chen, A.; Xu, L.; Cao, C.; Fang, J.; Myneni, R.B.; Pinzon, J.E.; Tucker, C.J.; Piao, S. Recent change of vegetation growth trend in China. Environ. Res. Lett. 2011, 6, 44027. [CrossRef]

48. Anselin, L. Under the hood issues in the specification and interpretation of spatial regression models. Agric. Econ. 2002, 27, 247-267. [CrossRef]

49. Keitt, T.H.; Bjornstad, O.N.; Dixon, P.M.; Citron-Pousty, S. Accounting for spatial pattern when modeling organis-environment interactions. Ecography 2002, 25, 616-625. [CrossRef]

50. Smith, P.A. Autocorrelation in logistic regression modelling of species distributions. Glob. Ecol. Biogeogr. Lett. 1994, 4, 47-61. [CrossRef]

51. Diniz-Filho, J.A.F.; Hawkins, B.A.; Bini, L.M.; De Marco, P.; Blackburn, T.M. Are spatial regression methods a panacea or a Pandora's box? A reply to Beale et al. (2007). Ecography 2007, 30, 848-851. [CrossRef]

52. Dormann, F.C.; McPherson, J.M.; Araújo, M.B.; Bivand, R.; Bolliger, J.; Carl, G.; Davies, R.G.; Hiezel, A.; Jetz, W.; Kissling, W.D.; et al. Methods to account for spatial autocorrelation in the analysis of species distributional data: A review. Ecography 2007, 30, 609-628. [CrossRef] 
53. Bickford, S.A.; Laffan, S.W. Multi-extent analysis of the relationship between pteridophyte species richness and climate. Glob. Ecol. Biogeogr. 2006, 15, 588-601. [CrossRef]

54. Kissling, W.D.; Carl, G. Spatial autocorrelation and the selection of simultaneous autoregressive models. Glob. Ecol. Biogeogr. 2008, 17, 59-71. [CrossRef]

55. Serrat-Capdevila, A.; Scott, R.L.; Shuttleworth, J.; Valdés, J.B. Estimating evapotranspiration under warmer climates: Insights from a semi-arid riparian system. J. Hydrol. 2011, 399, 1-11. [CrossRef]

56. Sala, O.E.; Lauenroth, W.K. Small rainfall events: An ecological role in semiarid regions. Oecologia 1982, 53, 301-304. [CrossRef]

(C) 2020 by the authors. Licensee MDPI, Basel, Switzerland. This article is an open access article distributed under the terms and conditions of the Creative Commons Attribution (CC BY) license (http://creativecommons.org/licenses/by/4.0/). 